\title{
Effects of different water activities on the stability of carotenoids in puff-dried yellow peach powder
}

\section{during storage}

\author{
Gorby Gonzalles ${ }^{1,2}$, Ningning Geng ${ }^{3}$, Shuwei Luo ${ }^{4}$, Chenchen Zhang ${ }^{3}$ Caie Wu ${ }^{4}$ Dajing Li ${ }^{1}$, Ying Li ${ }^{1}$, \\ Jiangfeng Song ${ }^{1,3,4 *}$
}

${ }^{1}$ Institute of Agro-Product Processing, Jiangsu Academy of Agricultural Sciences, Nanjing, Jiangsu, China; ${ }^{2}$ Jinling College, Nanjing Normal University, Nanjing, Jiangsu, China; ${ }^{3}$ School of Food and Biological Engineering, Jiangsu University, Zhenjiang, Jiangsu, China; ${ }^{4}$ College of Light Industry and Food Engineering, Nanjing Forestry University, Nanjing, Jiangsu, China

*Corresponding author: Jiangfeng Song, Institute of Agro-Product Processing, Jiangsu Academy of Agricultural Sciences, Nanjing, Jiangsu, 210014, China. Email: songjiangfeng102@163.com

Received: 23 July 2021; Accepted: 7 September 2021; Published: 23 September 2021

(c) 2021 Codon Publications

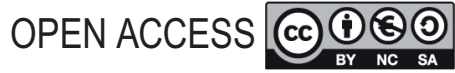

ORIGINAL ARTICLE

\begin{abstract}
The stability of carotenoids in puff-dried yellow peach powder during commercial storage under different water activity conditions was studied. The results showed that when the corresponding water activity was above 0.576 , the loss of adsorbed water in yellow peach powder was closely related to the crystallinity of the amorphous sugar matrix. However, the adsorption isotherms confirmed by water absorption behavior, X-ray diffraction (XRD) patterns, and scanning electron microscopy did not clearly indicate this loss of adsorbed water. The content changes of individual carotenoids (lutein, zeaxanthin, $\beta$-cryptoxanthin, $\alpha$-carotene, and $\beta$-carotene) during storage followed pseudo first-order kinetics, and the degradation of lutein and zeaxanthin occurred quickly over time. The stability of total carotenoids gradually increased when the water activity was less than 0.576 , but the carotenoids degraded sharply when the water activity was between 0.753 and 0.843 . The loss of carotenoids was related to the water absorption and crystallization of the sugar matrix in the powder.
\end{abstract}

Keywords: carotenoid stability; puff-dried yellow peach powder; sugar crystallization; storage condition; water activity

\section{Introduction}

Numerous studies have shown that colorful fruits and vegetables contain a variety of phytochemicals that are associated with significant health benefits (Liu, 2013). Yellow fleshed peaches are a good source of carotenoids, ascorbic acid, and dietary fiber. They have powerful antioxidant and immune-enhancing functions (Falchi et al., 2013; Fiedor and Burda, 2014). They are widely consumed in fresh and processed form, especially as canned fruits. However, the high moisture content (approximately 87\%) of the peach fruit will cause a rapid decline in quality after harvest. Therefore, the dehydration process is used to preserve peach fruits and improve storage stability by reducing water activity $\left(\mathrm{a}_{\mathrm{w}}\right)$ to minimize physical and chemical reactions that may occur during storage (Mathlouthi, 2001).

Especially in the fruit powder form, because $\mathrm{a}_{\mathrm{w}}$ becomes very low, the moisture content is at a microbiological safety level. But, the fruit powder is an amorphous dry granular material, which is highly hygroscopic and susceptible to water plasticization and glass transition $\left(\mathrm{T}_{\mathrm{g}}\right)$, including physical changes, such as collapse or powder sticking and sugar crystallization, as well as color changes (Fongin et al., 2017). It is also evident that 
chemical reactions will be delayed due to the fact that the reactants are diluted in a highly viscous medium (Bhandari and Howes, 1999). Due to the highly unsaturated structure, carotenoids in yellow peach powder are prone to degradation during storage owing to their exposure to oxygen, high temperature, and light or prooxidant molecules. These attributes have been investigated in various food and model systems (Lavelli et al., 2007; Oliveira et al., 2015; Prado et al., 2006). It is interesting that the loss of carotenoids was also related with the crystallization of high-sugar food matrix, but the moisture content of the amorphous phase was a major determinant of carotenoid retention (Elizalde et al., 2002). Harnkarnsujarit and Charoenrein (2011) reported that the stability of $\beta$-carotene in freeze-dried mango powder was affected by different relative vapor pressure (RVP) conditions. Lavelli et al. (2007) observed a decrease in rate constants of $\beta$-carotene with an increase of water activity up to about 0.314 in freeze-dried carrots. Prado et al. (2006) also found that $\beta$-carotene was mainly lost when it was stored at higher relative humidity. Although several studies were dealing with the kinetics of the crystallization from amorphous sugar and related to the storage conditions (Buera et al., 2005; Udomkun et al., 2015), little was known about the carotenoid stability of yellow peach powder as affected by water activity and sugar crystallization.

Explosion-puffing drying is a promising dehydration method gradually applied to the preparation of fruit powder, which can save drying time and energy as well as change the texture of dried fruit products (Lyu et al., 2015; Rahman, 2001). The purpose of this study was to investigate the changes in sugar crystallization and carotenoid retention rate in puff-dried yellow peach powder stored under different water activities, in order to clarify the relationship between sugar crystallization and carotenoid stability in yellow peach powder. It provides a theoretical basis for increasing the carotenoid retention rate of fruit powder during storage.

\section{Materials and Methods}

\section{Raw materials}

The yellow peach (Amygdalus persica L.) variety "Jinhui" was obtained from the Peach Central Production Area of the Institute of Horticulture, Jiangsu Academy of Agricultural Sciences, Nanjing, China. Generally, the total soluble solid content of yellow fleshed peach fruits was estimated to be between 10 and $20^{\circ}$ Brix. Peach fruits were picked by hand when they were commercially mature and evaluated by peel color. The harvested yellow peach fruits were peeled and pitted and cut into $1 \mathrm{~cm}$ thick slices. The initial moisture content of the slices was 84 to $86 \%$ (w. b.). The fruit slices were blanched and stored in a deep refrigerator at $-40^{\circ} \mathrm{C}$ before being dehydrated.

\section{Preparation of yellow peach powder by explosion-puffing drying}

The yellow peach slices were air-dried at $80^{\circ} \mathrm{C}$ for $2 \mathrm{~h}$, stored in a freezer for $12 \mathrm{~h}$, and then puffed and dried by using a QDPH-5 Electric Heating-Puffing Equipment (Tianjin Materials Technology Limited, Tianjin, China), with a puffing pressure difference of $0.1 \mathrm{MPa}$, vacuum drying temperature of $70^{\circ} \mathrm{C}$, and vacuum drying time of 150 min until the moisture content of the final product was less than $5 \%$. Thereafter, the samples were stored for 3 days in a vacuum desiccator, which contained silica gel to remove residual water. According to Zouaoui et al. (2016), the samples were considered to have "zero" water content. The fruit samples were milled and homogenized using a grinder until the particle size was in the range of $100-150 \mu \mathrm{m}$. The powder samples were packed in aluminum foil and ready for further use.

\section{Water sorption analysis}

Puff-dried yellow peach powder $(100 \mathrm{mg})$ was prepared in an aluminum pack and stored in a vacuum dryer at ambient temperature $\left(25^{\circ} \mathrm{C}\right)$ for $288 \mathrm{~h}$, which contained different saturated salt solutions: $\mathrm{LiCl}, \mathrm{CH}_{3} \mathrm{COOK}, \mathrm{MgCl}_{2}$, $\mathrm{K}_{2} \mathrm{CO}_{3}, \mathrm{NaBr}, \mathrm{NaCl}$, and $\mathrm{KCl}$ with RVP of $11.3,22.5,32.8$, $43.2,57.6,75.3$, and $84.3 \%$, respectively (Greenspan, 1977). Before weighing, each package was covered with a lid to minimize the transfer of water released from the vacuum dryer through the air. The powder sample was weighed at each 24-h interval and water content of each sample as a function of time was taken from the average weight of triplicate samples.

The data used to analyze the water sorption behavior of the puff-dried yellow peach powder were plotted relating the water activity $\left(\mathrm{a}_{\mathrm{w}}\right)$ as a function of the environmental equilibrium relative humidity and the storage time. The Guggenheim-Anderson-De Boer (GAB) mathematical model (Equation 1) was fitted to the water sorption data using OriginPro 8.5 analysis software (Fan and Roos, 2017).

$$
\frac{\mathrm{m}}{\mathrm{m}_{\mathrm{m}}}=\frac{\mathrm{CKa}_{\mathrm{w}}}{\left(1-\mathrm{Ka}_{\mathrm{w}}\right)\left(1-\mathrm{Ka}_{\mathrm{w}}+C K \mathrm{a}_{\mathrm{w}}\right)}
$$

where $\mathrm{m}$ was the equilibrium dry basis moisture content, $\mathrm{g} \cdot \mathrm{g}^{-1} ; \mathrm{a}_{\mathrm{w}}$ was the water activity, $\mathrm{m}_{\mathrm{m}}$ was the monolayer molecular layer moisture content, $\mathrm{g} \cdot \mathrm{g}^{-1}$; and $\mathrm{C}$ and $\mathrm{K}$ were model parameters. 


\section{X-ray diffraction}

The X-ray diffraction (XRD) analysis of puff-dried yellow peach powder was performed with an X-ray diffractometer (D2 ADVANCE, Bruker, Germany) with nickelfiltered $\mathrm{Cu} K \alpha$ radiation of $\lambda=1.54056 \AA$ wavelength and operated at $30 \mathrm{kV}$ and $10 \mathrm{~mA}$, as described by Zeng et al. (2016) with some modifications. The scattered radiation was detected in the angular range of $4-50^{\circ}$ and a diffraction angle of $2 \theta$, with a scanning speed of $5^{\circ}(2 \theta) / \mathrm{min}$ and step size increase of $0.02^{\circ} 2 \theta / 0.5 \mathrm{~S}$. The types of sugar crystals formed in yellow peach powder were identified from the location of the characteristic peaks in XRD patterns.

\section{Scanning electron microscope}

A scanning electron microscope (SEM) (FEI Quanta 200, FEI Company, Hillsboro, OR, USA) was used to examine and photograph the morphological characteristics of the puff-dried yellow peach powder at an accelerating voltage of $20 \mathrm{KV}$. The samples were observed at $1000 \times$ magnifications. The powdered samples were sprinkled on a double-sided stick tape placed on aluminum stubs and were covered with a gold-palladium layer (E-1010, Hitachi, Japan) in high vacuum.

\section{Changes of carotenoid content in yellow peach powder during storage}

The puff-dried yellow peach powder wrapped in an aluminum foil bag was placed in evacuated desiccators with different RVP conditions, and stored at an ambient temperature of $25^{\circ} \mathrm{C}$ for 90 days. Samples taken at each storage interval were kept in a freezer $\left(-20^{\circ} \mathrm{C}\right)$ until used for carotenoid analysis in triplicate.

Carotenoids in fruit powder samples were extracted and determined according to the previous method (Song et al., 2016a, b). Shortly, $1 \mathrm{~g}$ of sample powder was weighed and mixed with $30 \mathrm{~mL}$ of hexane-ethanol-acetone-toluene (10: 6: 7:7) and allowed to keep at room temperature in the dark for $4 \mathrm{~h}$. After that, $2 \mathrm{~mL}$ of $40 \%$ $\mathrm{KOH}-$ methanol solution was added, placed under nitrogen gas for complete saponification, and then $30 \mathrm{~mL}$ of $\mathrm{n}$-hexane and $38 \mathrm{~mL}$ of $10 \%$ of sodium sulfate were added for partitioning of the carotenoids. The upper layer containing carotenoids was collected and analyzed by $\mathrm{C}_{30}{ }^{-}$ HPLC-DAD-MS. The identification of carotenoids was accomplished by comparing retention time, maximum ultraviolet (UV)-visible absorption, electron ionization, and chemical ionization mass spectroscopy fragmentation modes.

\section{Statistical analysis}

All experiments were in triplicate and the results were calculated as the average value \pm standard deviation of triplicate measurements. One-way analysis of variance (ANOVA) and Duncan's multiple range test were used to compare the samples. Significance was defined at $\mathrm{P}<$ 0.05 . Statistical analyses were performed using SAS 9.3 software (Inc., Cary, NC).

\section{Results and Discussion}

\section{Water sorption behavior}

Figure 1a showed the water sorption behaviors for puffdried yellow peach powder under various experimental RVP conditions at $25^{\circ} \mathrm{C}$. The samples at intermediate RVP level $\left(\mathrm{a}_{\mathrm{w}}>0.43\right)$ normally absorbed water until reaching a constant weight. At the RVP levels of $57.6-75.3 \%$, different behaviors were observed after $192 \mathrm{~h}$, indicating that some absorbed water was released from the sample. Harnkarnsujarit and Charoenrein (2011) also found the same behavior in freeze-dried mangoes at the RVP level of $43.2-68.9 \%$, and at $100 \mathrm{~h}$, an obvious unexpected peak of water sorption was observed. It was speculated that the relevant moisture absorption caused the glass transition temperature $(\mathrm{Tg})$ to drop below room temperature $\left(25^{\circ} \mathrm{C}\right)$, and sugar crystallization in the powder form might occur (Buera et al., 2005; Iglesias et al., 2017). The steady-state water content of puff-dried yellow peach powder was plotted as a function of $\mathrm{a}_{\mathrm{w}}$ (Figure $1 \mathrm{~b}$ ), and the GAB model fitted well with the experimental data $\left(R^{2}=0.9937\right)$ below $\mathrm{a}_{\mathrm{w}}$ 0.43. In this region, water had a predominant influence on the powder stability; it could dissolve constituents for being in the form of free molecules, which accelerated the undesirable reactions. The results obtained with the GAB model for puff-dried yellow peach powder were similar to those reported in other studies carried out with several fruits such as strawberry (Janowicz et al., 2007), apple, pear, melon (Agudelo-Laverde, 2012), and papaya (Udomkun et al., 2015). Moreover, the water sorption of the puff-dried yellow peach powder was 1.43\% higher than that of the hot-air dried samples, indicating that the puff-dried yellow peach powder was more hygroscopic during storage. The porous structure generated during explosion-puffing drying could certainly explain their higher water sorption (Lyu et al., 2015).

\section{Crystallization behavior}

The XRD patterns for puff-dried yellow peach powder stored at the RVP levels of 11.3, 32.8, 57.6, and 84.3\%, respectively, for $192 \mathrm{~h}$ were shown in Figure 2. Peak intensity for puff-dried yellow peach powder stored at $11.3 \%$ 
(A)

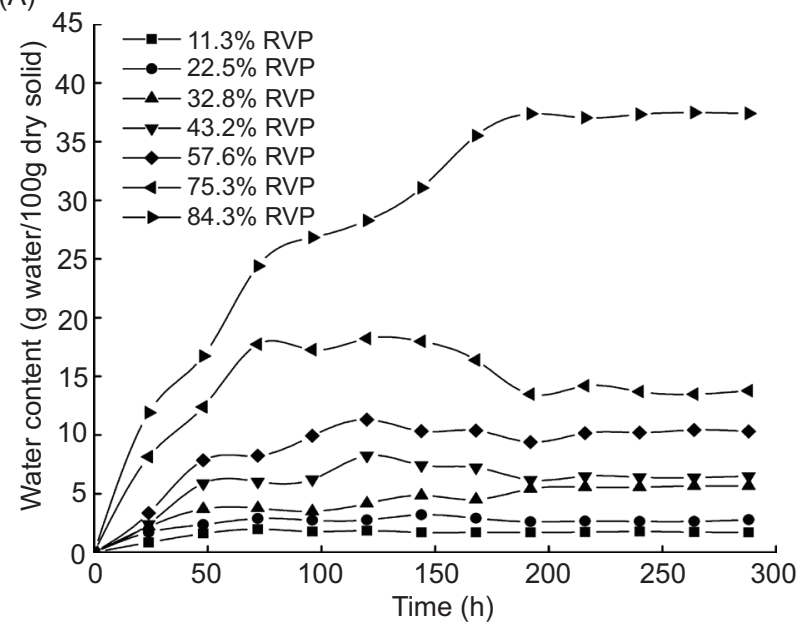

(B)

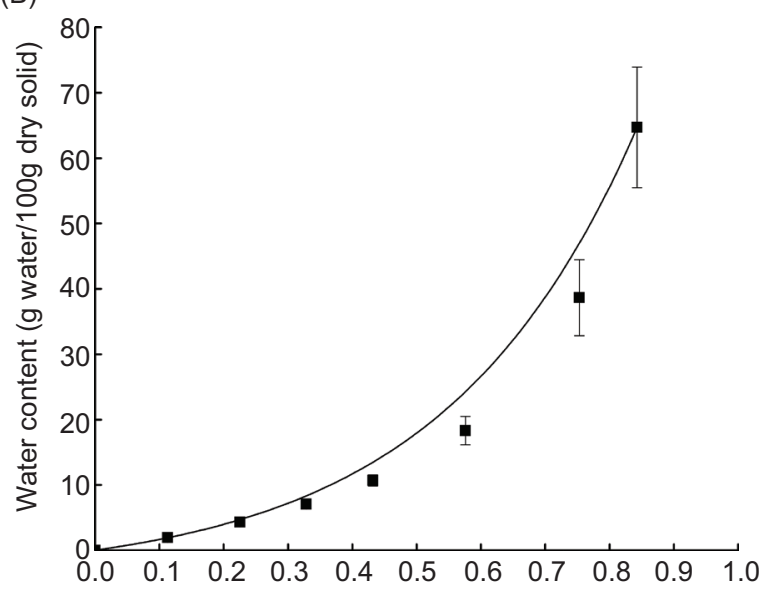

Figure 1. Water sorption behaviour of puff-dried yellow-fleshed peach powder.

RVP was extremely low, indicating that the sugar was crystallized slightly, and there was no obvious change in the physicochemical properties under such conditions. After $192 \mathrm{~h}$ of storage at $32.8 \% \mathrm{RVP}$, there was a sharp peak in the XRD pattern, confirming the appearance of the crystal structure. The crystal formation at 57.6\% RVP became more obvious. It was implied that the period of losing sorbed water could be regarded as the crystal growth stage, and the loss of adsorbed water had a good correlation with the crystallization of the amorphous sugar matrix.

The surface structures of the puff-dried yellow peach powder were presented in Figure 3. Figure 3A referred to the prior storage, and it demonstrated that there were no coarse precipitated particles in the amorphous structure. The samples stored at $11.3 \%$ RVP showed a soft surface but almost no coarse particles. As seen in Figure 3B-E, it was obvious that the samples at $32.8 \%$ RVP showed many coarse particles, and the large agglomerate with rough surfaces and interparticle adhesion were observed on the samples stored above 57.6\% RVP. The rough and rigid crystal state on the rough surface could be determined as the structural basis of sugar crystals (Alves et al., 2010). Therefore, those features indicated that crystallization was induced during storage, depending upon the different RVP levels. The crystallization process depended on the degree of supersaturation of the system, which in turn depended on the temperature, concentration, and sugar solubility. In this study, the main sugars in yellow peach powder are sucrose (54-75\% of the total SSC), glucose (9-21\%), fructose (3.25\%), and sorbitol (4-11\%); a high proportion of sucrose crystallized and released all the water that affected the hygroscopicity of yellow peach powder (Bassi et al., 2016; Buera et al., 2005). In addition, yellow peach powder also contained pectin and organic acids, which affected the final water content after sugar crystallization.

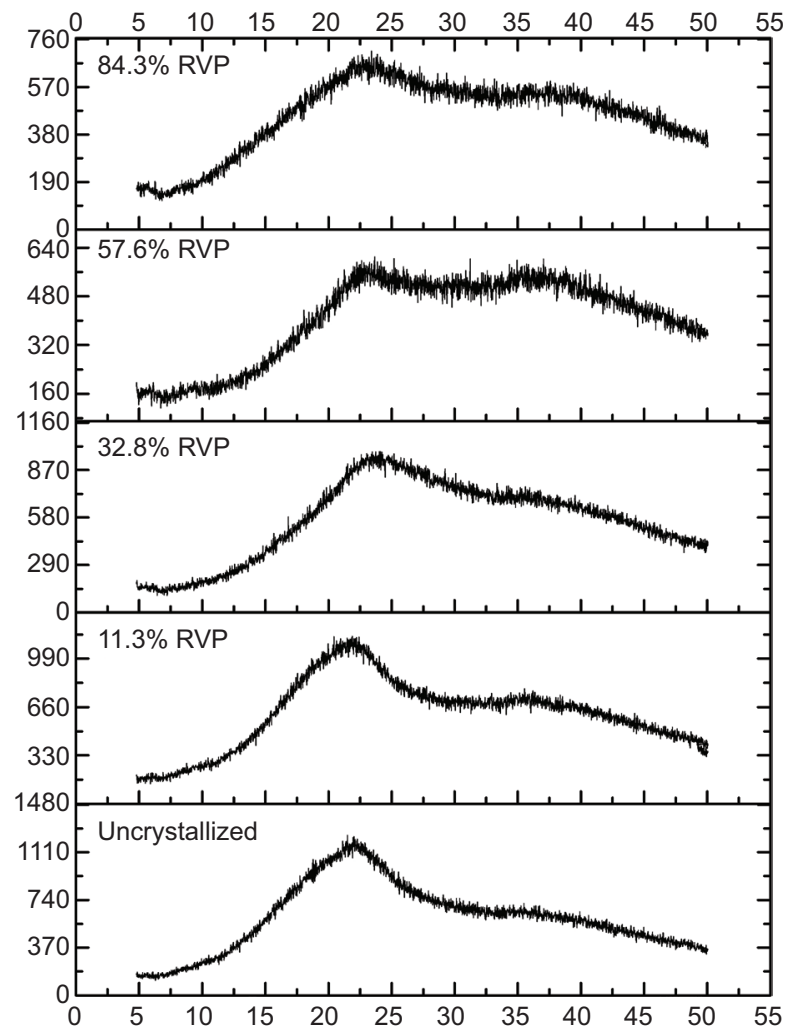

Figure 2. X-ray diffraction patterns of puff-dried yellowfleshed peach powder during the 8-day storage at $25{ }^{\circ} \mathrm{C}$ under different RVP conditions: (A) un-crystallized samples; (B) $11.3 \%$ RVP; (C) $32.8 \%$ RVP; (D) 57.6\% RVP; (E) $84.3 \%$ RVP.

\section{The degradation of carotenoids}

The degradation of total carotenoids in puff-dried yellow peach powder was studied under different storage RVPs as seen in Figure 4. The first-order rate constants 
(A)

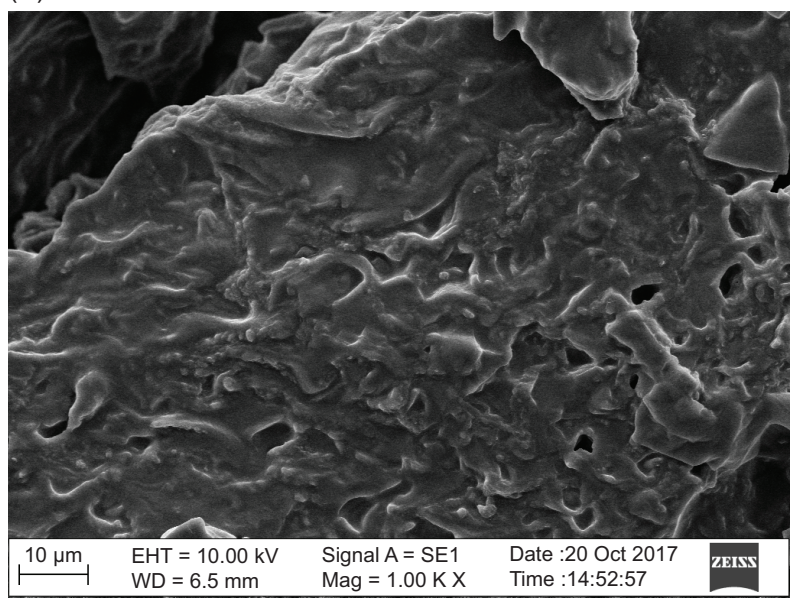

(C)

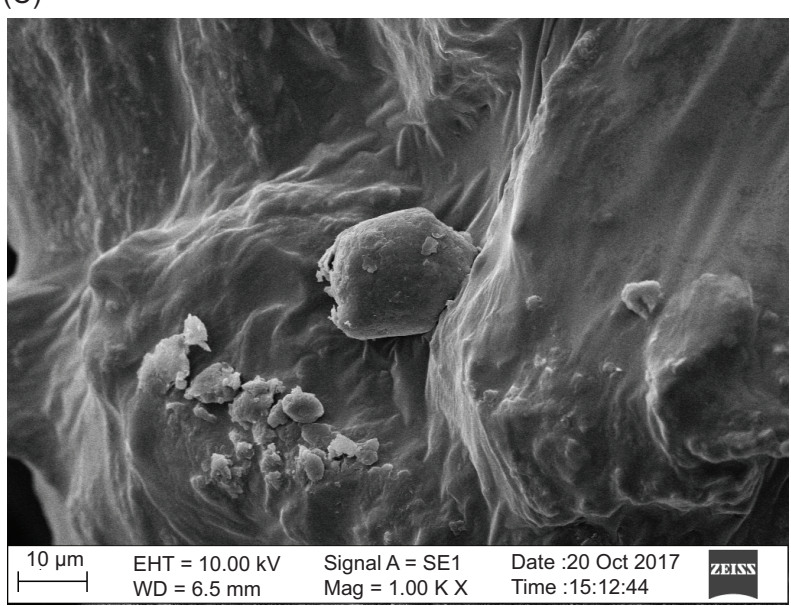

(B)

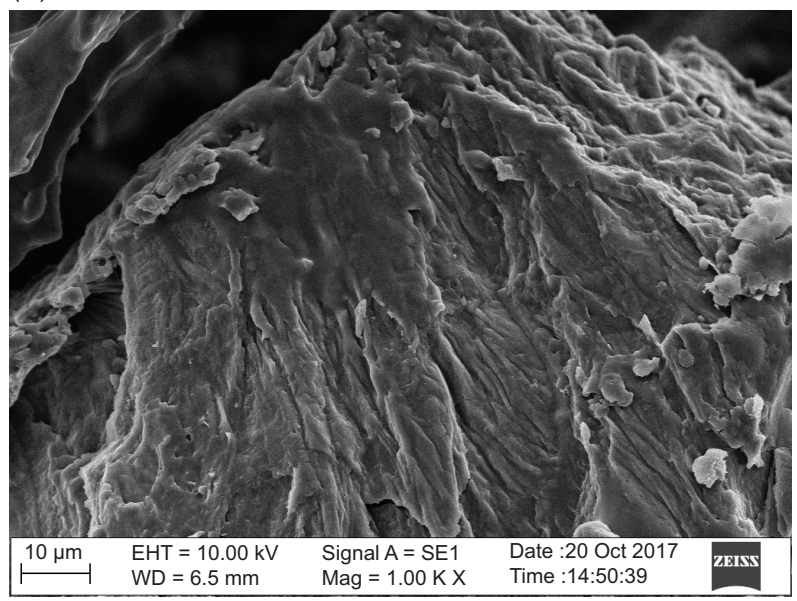

(D)

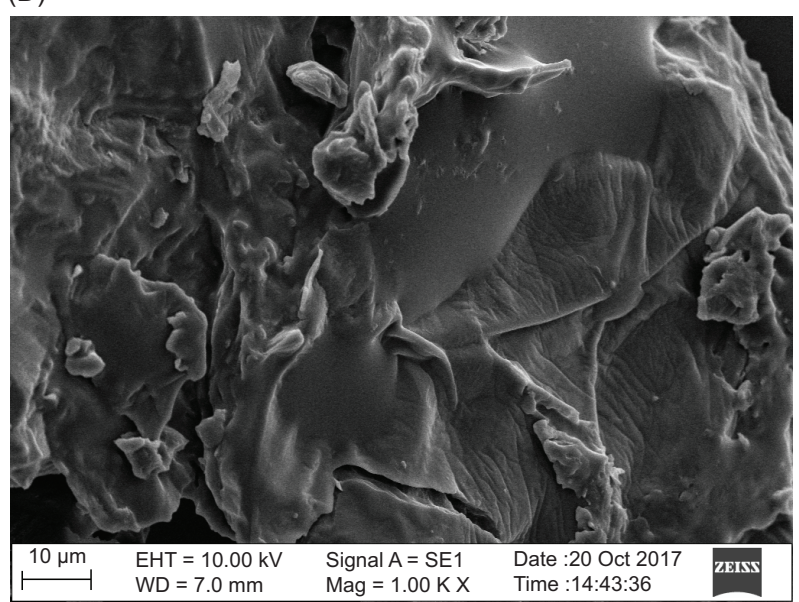

(E)

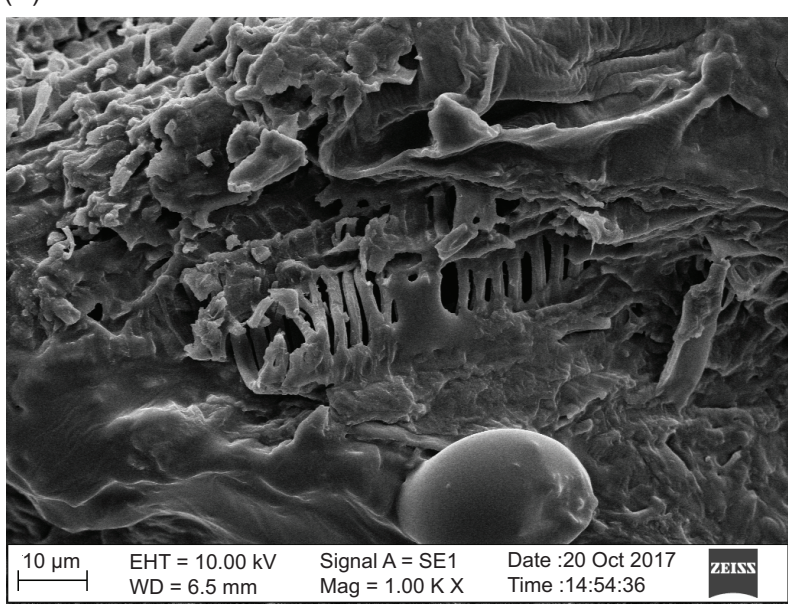

Figure 3. Scanning electron micrographs of puff-dried yellow-fleshed peach powder during the 8-day storage at $25{ }^{\circ} \mathrm{C}$ under different RVP conditions: (A) un-crystallized samples; (B) 11.3\% RVP; (C) $32.8 \%$ RVP; (D) $57.6 \%$ RVP; (E) $84.3 \%$ RVP.

of total carotenoids versus $\mathrm{a}_{\mathrm{w}}$ were plotted to show a typical U-shaped curve for most oxidation reactions. As $\mathrm{a}_{\mathrm{w}}$ increased to 0.328 , a decrease in the rate constant was observed. In the $a_{w}$ range of $0.328-0.576$, the carotenoids in fruit powder showed the maximum stability.
The decrease in the rate constant of carotenoids could be explained by the glass-rubber transition, which was assumed when the yellow peach powder was stored under $a_{w} 0.113$; it was in a glassy state and subsequently changed into a rubbery state when stored at $\mathrm{a}_{\mathrm{w}} 0.576$ (Fan and 
Roos, 2017). When the samples were in the glassy state, high porosity of matrices for puff-dried fruit powder allowed oxygen diffusion and, therefore, carotenoids degraded quickly (Prado et al., 2006; Selim et al., 2000).

However, when the fruit powder was stored above $a_{w}$ 0.753 , the degradation rate of carotenoids increased, and the highest rate constant was determined at $\mathrm{a}_{\mathrm{w}} 0.843$. This was attributed to the water absorption between the randomly spaced molecules in the noncrystalline system, which increased the oxidation rate by increasing the fluidity of the reactants (Alves et al., 2010; Lavelli et al., 2007). Obviously, the loss of carotenoids was related with the water absorption and crystallization of the sugar matrix from the powder. Buera et al. (2005) explained that when the matrix was amorphous, chemical reactions were delayed because the reactants were diluted in a highly viscous medium. Elizalde et al. (2002), and Harnkarnsujarit and Charoenrein (2011) found that matrix crystallization resulted in the loss of some encapsulated bioactive compounds, which made them more susceptible to oxygen exposure and subsequent degradation.

As shown in Table 1, with prolonged storage time, all individual carotenoids in puff-dried yellow peach powder

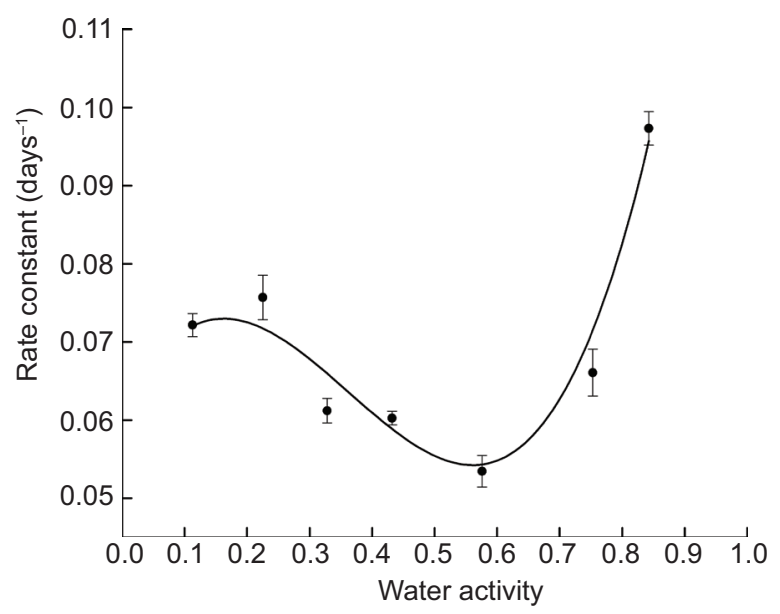

Figure 4. Observed and fitted values of the first-order degradation rate constants for total carotenoids in puff-dried yellow-fleshed peach powder at various water activities $\left(a_{w}\right)$. gradually lost. Lutein lost $34.4 \%$ after storage at $25^{\circ} \mathrm{C}$ for 90 days, whereas zeaxanthin, $\beta$-cryptoxanthin, $\alpha$-, and $\beta$-carotene lost $27.5,22.2,12.4$, and $16.3 \%$, respectively. The linear correlation coefficients $\left(\mathrm{R}^{2}\right)$ ranged from 0.899 to 0.975 (Figure 5), confirming that the degradation of each carotenoid was also following the first-order reaction. Przybysz et al. (2017) also determined a first-order reaction for the degradation of both $\alpha$-carotene and $\beta$-carotene. A similar degradation behavior was found between $\beta$-cryptoxanthin, $\alpha$-, and $\beta$-carotene, whereas lutein and zeaxanthin were found to degrade faster. It appeared that different types of carotenoids exhibited different susceptibilities to oxidation, and oxycarotenoids were more labile (Song et al., 2018). In addition, the carotenoid content of puff-dried yellow peach powder during storage varied according to its tested water activity. A spontaneous loss of carotenoids was observed in puff-dried yellow peach powder at all RVP levels during storage (Table 2). It was generally shown that high rate constants for individual carotenoids in fruit powder were all at high RVP levels. The RVP levels in the range of $43.2-57.6 \%$ corresponded to the lower degradation rate constants, indicating the maximum carotenoid stability;

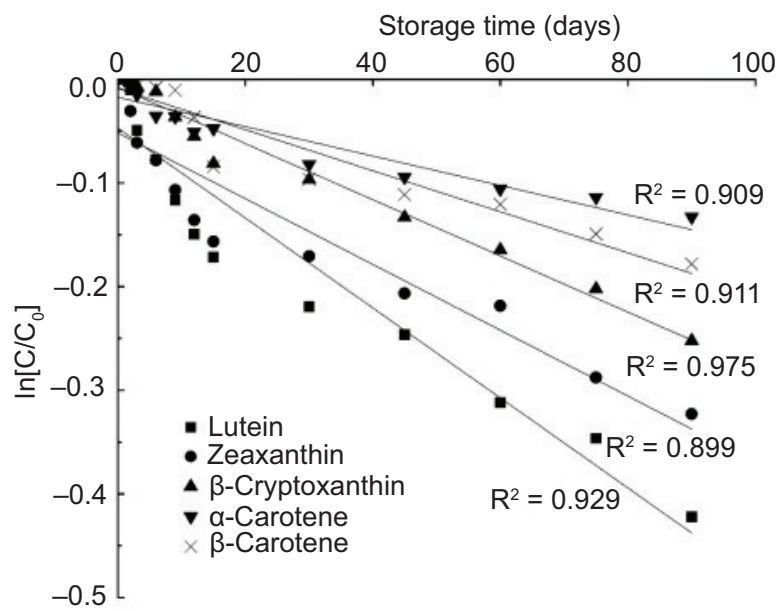

Figure 5. Kinetic evolution of lutein $(\square)$, zeaxanthin $(\bullet)$, $\boldsymbol{\beta}$-cryptoxanthin $(\boldsymbol{\Delta}), \boldsymbol{\alpha}$-carotene $(\boldsymbol{\nabla})$, and $\boldsymbol{\beta}$-carotene $(\mathbf{x})$ in yellow-fleshed peach powder at $a_{w}=0.576$ as a function of storage time.

Table 1. Change in the content of individual carotenoids in yellow-fleshed peach powder during 90 -day storage at $a_{w}=0.576$.

\begin{tabular}{|c|c|c|c|c|c|}
\hline $\begin{array}{l}\text { Time } \\
\text { (days) }\end{array}$ & $\begin{array}{l}\text { Lutein } \\
\text { ( } \mu \mathrm{g} / \mathrm{g} \text { d. } w .)\end{array}$ & $\begin{array}{l}\text { Zeaxanthin } \\
\text { ( } \mu \mathrm{g} / \mathrm{g} \text { d. } w .)\end{array}$ & $\begin{array}{c}\beta \text {-Cryptoxanthin } \\
\text { ( } \mu \mathrm{g} / \mathrm{g} \text { d. w.) }\end{array}$ & $\begin{array}{l}\alpha \text {-Carotene } \\
\text { ( } \mu \mathrm{g} / \mathrm{g} \text { d. w.) }\end{array}$ & $\begin{array}{l}\beta \text {-Carotene } \\
\text { ( } \mu \text { g/g d. w.) }\end{array}$ \\
\hline 0 & $7.78 \pm 0.02^{\mathrm{a}}$ & $16.88 \pm 0.01^{a}$ & $11.83 \pm 0.01^{\mathrm{a}}$ & $5.41 \pm 0.01^{\mathrm{a}}$ & $9.53 \pm 0.01^{a}$ \\
\hline 30 & $6.25 \pm 0.05^{b}$ & $14.23 \pm 0.08^{b}$ & $10.74 \pm 0.08^{b}$ & $4.99 \pm 0.02^{b}$ & $8.66 \pm 0.07^{b}$ \\
\hline 60 & $5.70 \pm 0.11^{c}$ & $13.56 \pm 0.13^{c}$ & $10.04 \pm 0.14^{b}$ & $4.87 \pm 0.01^{b}$ & $8.45 \pm 0.14^{b}$ \\
\hline 90 & $5.10 \pm 0.02^{c}$ & $12.22 \pm 0.14^{d}$ & $9.19 \pm 0.01^{c}$ & $4.74 \pm 0.03^{b}$ & $7.98 \pm 0.01^{\circ}$ \\
\hline
\end{tabular}

Different letters in the same row indicate significant differences $(p<0.05)$. 


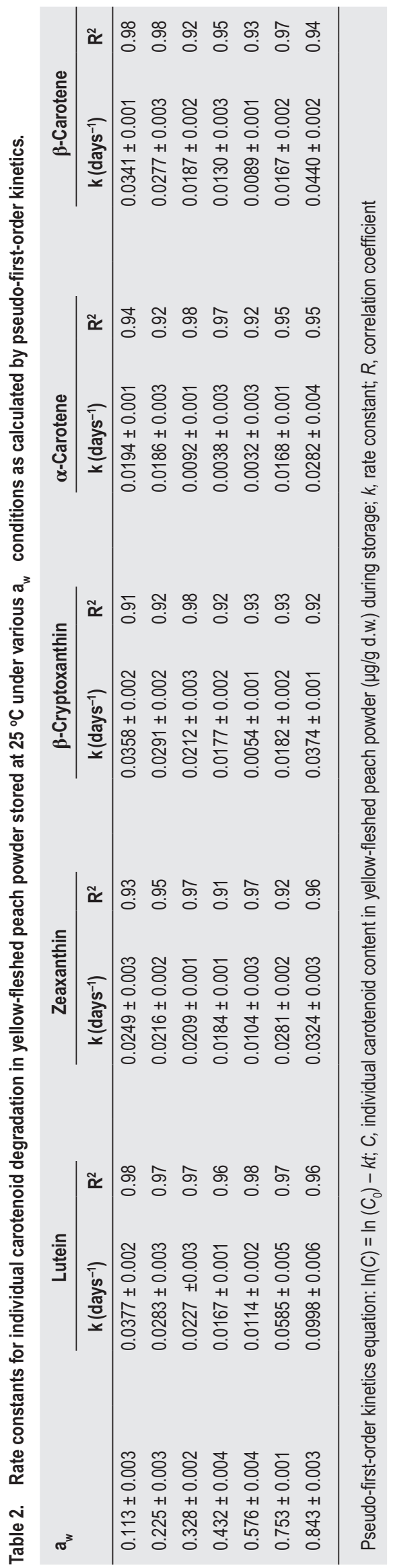

however, it was not precisely located within the estimated average value for each water activity. The oxidative degradation of carotenoids in fruit powder during storage was strongly related to the occurrence of oxygen at each RVP level. The oxidative degradation followed a free radical mechanism wherein water absorption and crystallization influenced the oxidation modes of carotenoid loss (Buera et al., 2005).

\section{Conclusions}

Our study revealed that the loss of sorbed water in puffdried yellow peach powder was well correlated with the crystallization of an amorphous sugar matrix at a corresponding RVP greater than or equal to $57.6 \%$. The XRD pattern and SEM image of the sample confirmed sharp peak patterns when the powder was stored at 57.6 and 84.3\% RVP, indicating the formation of high amounts of crystals in amorphous samples. Moreover, the carotenoid stability of the puff-dried yellow peach powder during storage increased as the RVP level increased up to $57.6 \%$ and sharply decreased at the RVP level of $75.3-84.3 \%$. The degradation of carotenoids was related to the crystallization of sugar and water activity during storage. Thus, the control of water activity might be important for improving the carotenoid stability of puff-dried yellow peach powder.

\section{Acknowledgements}

The work was supported by Grants-in-Aid for the Independent Innovation Fund Project of Agricultural Science and Technology in Jiangsu Province (Project number: CX (20) 3047), the project of Natural Science Foundation of Jiangsu Province (Project number: BK20201241), and Primary Research and Development Plan of Jiangsu Province (Project number: BE2019324).

\section{References}

Agudelo-Laverde, M., 2012. Water-solid interactions and their consequences on structural aspects, chromatic attributes and spatial distribution of light in freeze-dried fruits. PhD thesis, Buenos Aires, Argentine.

Alves, C.C.D.O., Resende, J.V.D., Prado, M.E.T. and Cruvinel, R.S.R., 2010. The effects of added sugars and alcohols on the induction of crystallization and the stability of the freeze-dried peki (Caryocar brasiliense camb.) fruit pulps. LWT - Food Science and Technology 43(6): 934-941. https://doi.org/10.1016/j. lwt.2010.01.029

Bassi, D., Ilaria, M., Anna, S. and Debora, T., 2016. PEACH (Prunus persica (L.) Batsch). Nutritional composition of fruit cultivars. Department of Agricultural and Environmental Sciences, 
University of Milan, Milano, Italy. https://doi.org/10.1016/ B978-0-12-408117-8.00023-4

Bhandari, B.R. and Howes, T., 1999. Implication of glass transition for the drying and stability of dried foods. Journal of Food Engineering 40(1-2): 71-79. https://doi.org/10.1016/ s0260-8774.(99)00039-4.

Buera, P., Schebor, C. and Elizalde, B., 2005. Effects of carbohydrate crystallization on stability of dehydrated foods and ingredient formulations. Journal of Food Engineering 67(1-2): 157-165. https://doi.org/10.1016/j.jfoodeng.2004.05.052

Elizalde, B., Herrera, M.L. and Buera, P., 2002. Retention of $\beta$-carotene encapsulated in a trehalose-based matrix as affected by water content and sugar crystallization. Journal of Food Science 67: 3039-3045. https://doi.org/10.1111/j.1365-2621.2002.tb08856.x

Falchi, R., Vendramin, E., Zanon, L., Scalabrin, S., Cipriani, G., Verde, I., Vizzotto, G. and Morgante, M., 2013. Three distinct mutational mechanisms acting on a single gene underpin the origin of yellow flesh in peach. Plant Journal 76(2): 175-187. https://doi.org/10.1111/tpj.12283

Fan, F. and Roos, Y.H., 2017. Structural strength and crystallization of amorphous lactose in food model solids at various water activities. Innovative Food Science \& Emerging Technologies 40: 27-34. https://doi.org/10.1016/j.ifset.2016.06.011

Fiedor, J. and Burda, K., 2014. Potential role of carotenoids as antioxidants in human health and disease. Nutrients 6(2): 466-488. https://doi.org/10.3390/nu6020466

Fongin, S., Kawai, K., Harnkarnsujarit, N. and Hagura, Y., 2017. Effects of water and maltodextrin on the glass transition temperature of freeze-dried mango pulp and an empirical model to predict plasticizing effect of water on dried fruits. Journal of Food Engineering 210: 91-97. https://doi.org/10.1016/j. jfoodeng.2017.04.025

Greenspan, L., 1977. Humidity fixed points of binary saturated aqueous solutions. Journal of Research of the National Bureau of Standards 81(1): 89-96. https://doi.org/10.6028/jres.081A.011

Harnkarnsujarit, N. and Charoenrein, S., 2011. Influence of collapsed structure on stability of $\beta$-carotene in freeze-dried mangoes. Food Research International 44: 3188-3194. https://doi. org/10.1016/j.foodres.2011.08.008

Iglesias, H., Galmarini, M.V., Barrios, L.F.D. and Chirife, J., 2017. Kinetics of water sorption and sugar crystallization in freezedried bananas previously immersed in concentrated sucrose and trehalose solution. Anales des la Asociacion Quimica Argentina 104(1): 11-20.

Janowicz, M., Lenart, A. and Idzikowska, W., 2007. Sorption properties of osmotically-dehydrated and freeze-dried strawberries. Polish Journal of Food and Nutrition Sciences 57(1): 69-76.

Lavelli, V., Zanoni, B. and Zaniboni, A., 2007. Effect of water activity on carotenoid degradation in dehydrated carrots. Food Chemistry 104(4): 1705-1711. https://doi.org/10.1016/j. foodchem.2007.03.033

Liu, R.H., 2013. Health-promoting components of fruits and vegetables in the diet. Advances in Nutrition 4(3): 384S-392S. https:// doi.org/10.3945/an.112.003517
Lyu, J., Zhou, L.Y., Bi, J.F., Liu, X. and Wu, X.Y., 2015. Quality evaluation of yellow peach chips prepared by explosion puffing drying. Journal of Food Science and Technology-Mysore 52(12): 8204-8211. https://doi.org/10.1007/s13197-015-1906-0

Mathlouthi, M., 2001. Water content, water activity, water structure and the stability of foodstuffs. Food Control 12(7): 409-417. https://doi.org/10.1016/S0956-7135(01)00032-9

Oliveira, A., Alexandre, E.M.C., Coelho, M., Barros, M.R., Almeida, D.P.F. and Pintado, M., 2015. Peach polyphenol and carotenoid content as affected by frozen storage and pasteurization. LWT - Food Science and Technology 66: 361-368. https:// doi.org/10.1016/j.lwt.2015.10.037

Prado, S.M., Buera, M.P. and Elizalde, B.E., 2006. Structural collapse prevents $\beta$-carotene loss in a supercooled polymeric matrix. Journal of Agricultural and Food Chemistry 54(1): 79-85. https://doi.org/10.1021/jf051069z

Przybysz, M.A., Szterk, A., Symoniuk, E., Gaszczyk, M. and Dluzewska, E., 2017. $\alpha$-carotene and $\beta$-carotene stability during storage of microspheres obtained from spray-dried microencapsulation technology. Polish Journal of Food and Nutrition Sciences 68: 45-55. https://doi.org/10.1515/pjfns-2017-0006

Rahman, M.S., 2001. Toward prediction of porosity in foods during drying: a brief review. Drying Technology 19(1): 1-13. https:// doi.org/10.1081/DRT-100001349

Selim, K., Tsimidou, M. and Biliaderis, C.G., 2000. Kinetic studies of degradation of saffron carotenoids encapsulated in amorphous polymer matrices. Food Chemistry 71(2): 199-206. https://doi. org/10.1016/S0308-8146(00)00156-4

Song, J., Li, D., He, M., Chen, J. and Liu, C., 2016a. Comparison of carotenoid composition in immature and mature grains of corn (Zea mays L.) varieties. International Journal of Food Properties 19(2): 351-358. https://doi.org/10.1080/10942912.2015.1031245

Song, J., Li, D., Liu, N., Liu, C., He, M. and Zhang, Y., $2016 \mathrm{~b}$. Carotenoid composition and changes in sweet and field corn (Zea mays) during kernel development. Cereal Chemistry 93(4): 409-413. https://doi.org/10.1094/CCHEM-11-15-0230-N

Song, J., Wei, Q., Wang, X., Li, D., Liu, C., Zhang, M. and Meng, L., 2018. Degradation of carotenoids in dehydrated pumpkins as affected by different storage conditions. Food Research International 107: 130-136. https://doi.org/10.1016/j.foodres.2018.02.024

Udomkun, P., Argyropoulos, D., Nagle, M., Mahayothee, B. and Müller, J., 2015. Sorption behavior of papayas as affected by compositional and structural alterations from osmotic pretreatment and drying. Journal of Food Engineering 157: 14-23. https://doi.org/10.1016/j.jfoodeng.2015.01.022

Zeng, F., Zhu, S., Chen, F., Gao, Q. and Yu, S., 2016. Effect of different drying methods on the structure and digestibility of short chain amylose crystals. Food Hydrocolloids 52: 721-731. https://doi.org/10.1016/j.foodhyd.2015.08.012

Zouaoui, A., Ghedira, L.Z. and Nasrallah, S., 2016. Experimental investigation of air dehumidification and regeneration operations using packed bed of silica gel particles. International Journal of Heat and Technology 34(1): 103-109. https://doi. org/10.18280/ijht.340115 